\title{
Handcrafting Attachment: A User-Centered Approach
}

George S. Lowry, Randolph-Macon College, USA

Catherine L. Franssen, Randolph-Macon College, USA

Jonathan E. Lowry, University of Cincinnati, USA

\begin{abstract}
Management, above all, is the controlling element responsible for coordinating the three basic business functions; production, marketing, and finance. Mechanisms exist to facilitate the finance function with influence coming from outside regulatory bodies such as the AICPA, IIA, SEC, and other regulators. Integrating the finance function into organizations, then, becomes somewhat generic (although some would argue this point). Coordinating the functions of marketing and production is a much more difficult endeavor because it lacks the standardization seen in finance. This paper suggests employing a more user-focused approach as a means to improving the overall quality of products, and eventually, the success of the organization. Specifically, this paper explores the role of the human brain in the calculus of choice, discusses the role of consumer involvement as it leads to product attachment, and offers suggestions for employing contextual research to improve product design and quality.
\end{abstract}

Keywords: productions/operations management, effort-based rewards, product design, contextual research, natural elements, IKEA effect, ownership

\section{INTRODUCTION}

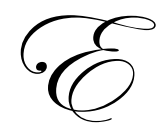

very organization, profit or non-profit, engages in three basic business functions; production, marketing, and finance. Simply put, production is engaged in transforming inputs into outputs. Marketing is concerned with communication-publics to organization, organization to publics, and intra-organization. Finance is responsible for tracking the flow of resources through the organization's environment. Complex mechanisms are constructed to accommodate these basic functions, but at their root, their focus is: make stuff, talk about stuff, and track stuff. Management's role is one of coordinating these three functions.

An old adage suggests marketing wants the production department to "produce what we can sell" while production wants marketing to "sell all we can produce". This paper suggests the underlying problem in producing quality products may be the disconnection between the desires of the consumers and the producers. Failing to recognize the factors affecting consumer preferences can lead to producing items that simply don't fit underlying needs. One way to address this is to incorporate into the mix a discipline used by designers, where the user becomes a key input in the decision making processes. Good design relies on an anthropological approach, called contextual research, to understanding user needs and wants, which informs a design-build-evaluate cycle eventuating in a product with a good fit. This "fit" meets the needs/wants of the end user, but also satisfies the aims of the firm to produce ethical products that generate profits.

This paper looks at some variables that influence product selection from several directions and emphasizes user-connection to the product as a possible trend in demand. For example, there is an increased interest and attachment to products demonstrating a connection to nature. Not to be confused with environmentalism, the inclusion of "natural elements" in product design has demonstrated benefits, not just in increased sales, but with higher customer satisfaction. Further, building attachment to a product can lead to increased loyalty, which can translate into future sales, but also can serve as a gauge of customer perceptions of firm and product quality. Making the right stuff continues to be the challenge for firms. Because this paper proposes potential solutions to this 
challenge, the next section explores how the human mind accepts natural elements. Then, the focus shifts to the hands-on consumer, and finally, the paper addresses the search for the proper balance in engaging the consumer into the process.

\section{HUMAN EVOLUTION AND THE DESIGN OF PRODUCTS}

Humans have evolved with certain natural elements and customized them into tools to work with other natural elements. The human brain responds to these elements in very specific ways. The visual system responds differently to natural scenes (e.g. forests) than to man-made scenes (e.g. strip malls) (Coppola, White, Fitzpatrick \& Purves, 1998). The olfactory system responds to complex natural odors differently than isolated chemicals used by scientists and manufacturers (Lin, Shea, Katz, 2006). Many of these reactions reflect simple variation in the normal spectrum of response, and product designers can play with unexpected textures and materials to surprise and delight the senses; however, there are pathological responses to non-natural stimuli, some of which can be debilitating. For example, the blue light emitted from televisions, computers, and even Blackberries disrupts the release of melatonin which, subsequently, interrupts sleep habits (Lockley, Brainard, Czeisler, 2003). The average night's sleep is 7.5 hours today versus 9 hours in 1900 (Vgontzas, Bixler, Kales, 2000). This may be a boon to the sale of pharmaceutical sleep aids, but opportunities (and demand) for more natural "red" light settings are present for those attuned to the market.

Similarly, the evolution of manufactured goods has included the change in materials. The impossible trilogy, Cheap-Fast-Good, has taken advantage of these materials. Plastics, chemicals, and changing technology have shifted the way items are produced, but also the way they look and feel. The migration from tangible to virtual introduces a wonderful new space and exciting new products, but the lure of nature still holds sway. The value of objects made from natural materials is reflected in their higher prices, but also in the perceived quality of the object itself. This may be due to the greater amount of work involved in producing using natural elements (perhaps including hand-made aspects), may be implied as a moral valuation, or both.

Ascribing value to objects is the basis for the level of attachment to that object. While the value can derive from the object itself, so too can it be generated by the consumer's engagement.

\section{OWNERSHIP AND RESPONSIBILITY: THE HANDS-ON CONUNDRUM}

Attachment to products comes from the level of ownership and responsibility assumed by the consumer. Ownership can reside in holding the title or deed to personal or real property, but in the goods market, the sales receipt may not be enough. Owning means holding a personal claim on the object, and with that comes the responsibility to care for it. A few examples might help clarify this relationship.

In the 1950s, Betty Crocker sought to streamline the cake-making process by introducing "instant cake mix". The mix required only the addition of water. Housewives of the time didn't like the idea. The lack of investing effort into the process made it less than desirable, they felt they were cheating. The subsequent modification allowed the baker to add an egg (and later, cooking oil). Doing so provided the sense of ownership, and thus attachment to the product - the cake, in this instance.

The largest retail do-it-yourself furniture company gets it. Inexpensive-some say cheap-furniture that is flat-packed, picked by the customer from the racks, taken home, and put together by the customer is the means to an end. Assembling the furniture is a short step removed from building it, and this level of involvement creates such a level of pride of completion, ownership is claimed. Sometimes called the IKEA effect (or "I did it myself...") engagement is the key to attachment. Owners of this product proudly display it, take pride in it, and are reluctant to discard it (Airely 2010).

Home Depot, the largest home improvement specialty retailer is also the fourth largest retailer in the US; but one can also look to the success of craft stores and small-scale DIY projects to exemplify the lasting and gratifying nature of the Ikea effect. A Cub Scout pinewood derby is an event where the Cub Scouts build a small car using a boxed set of elements that includes a block of soft pine, 4 small nails, and 4 plastic wheels. They carve their 
own body shape, paint the cars and apply decals, use small nails as axles for the plastic wheels, and add small lead weights to meet design criteria. Once built, they gather to "race" their cars down a pre-built track. The fastest car wins the trophy. The real prize, however, is the pride displayed by the boys (and their parents - some of which were instrumental in building the car) when everyone has a good look at all the cars. The "show and tell" overshadows the race in importance. Many attics and storage closets contain pinewood derby cars that date back many years. The level of attachment to those painted blocks of wood arises from the effort employed to produce them.

There is an evolving literature on effort-based rewards (Lambert 2008). Simply put, engagement and effort stimulate the pleasure pathways of the brain, thus rewarding the behavior. These pathways evolved from thousands of years of hunting, gathering, farming, chopping, grinding, and cooking foods, as well as building shelters, creating and cleaning objects to furnish those shelters and deliver these foods, creating usable fabrics, and generating other necessities of life. Linking these challenging endeavors with the pleasurable sensations of being warm, dry, and full is an important function of the brain to encourage the person to continue in their efforts. Much of modern work is virtual; however the brain has not yet evolved to associate hours of computer time or a credit card swipe at Wal-mart with contented sensations. If products can be developed that encourage some level of physical effort on the part of the consumer, reward pathways may be triggered and the level of attachment -or loyalty- could be enhanced.

\section{Not Too Much, Though...}

On the other hand, too much ownership and responsibility can be a bad thing. Involvement, engagement, and effort can facilitate attachment, but the on-going responsibility to maintenance may out-strip the consumer's ability, and, therefore erode attachment. Additionally, the ease of engagement can facilitate taking true ownership. The easier the involvement: the stronger the sense of ownership. Anything limiting easy connection to the product can serve as a barrier to attachment. For example, without an elemental understanding of the materials, the consumer may be challenged to fix the item if it breaks. Further, in such settings, there may be no-one to call who can fix it.

Similarly, if the DIY product is too difficult to assemble or the assembly requires specialty tools, attachment can be thwarted. Equally destructive is the case where the instructions are not intuitively understood. Many can identify with the feeling of helplessness when faced with hundreds of parts-including nuts, bolts, and screws - strewn across the floor (perhaps late the night before one hopes to give the gift to a child). The picture on the box looks like a wagon, but the instructions, written in a loosely-defined version of English, punctuated by an iconic language interpretable only by the illustrator, provide little help. Once completed, there is much relief, but little attachment to the final product.

Customization is often touted as a way to build attachment, but perils lie here, too. On the one hand, ownership and enhanced attachment through personal identification with the object can result from selecting such variables as color, finish, and other accoutrements. However, when selecting from a restricted set of options, not only is uniqueness not guaranteed, but one must be aware that "choosing is not creating" (Crawford, 2009) and without genuine creation, one risks a strong sense of attachment.

\section{IN SEARCH OF AN ANSWER}

There is a difficult balance to be struck in making the design decisions. Consumers make decisions using their time to investigate options and their money to purchase products. The trade-offs are evinced in selecting expensive products offering performance guarantees and service after the sale against the less expensive, throwaway products. However, the IKEA effect demonstrates the impact attachment has even with less expensive products, so the trade-offs are not as clear-cut as might be assumed.

In much the same way, the hands-on aspect of products creates an uncertain outcome. Up to a point, engagement in building the product creates attachment, but too much effort reduces the connection, and thus the reward. And hands-on is not limited to the assembly of the product. The visual and tactile perceptions of the product provide a source of feedback that, in itself, is a reward for ownership (Norman, 2002.) 
Involving the user is a fundamental approach in creating products that will meet the perceived needs and wants of the consumer. Significant contextual research, examining the underlying motives of the consumers, is an important and often neglected step in the process. Prototyping products and putting them in the hands of users is a simple, but necessary way to evaluate the efficacy of the product, and also to gauge the level of attachment they feel. Feedback from the practical testing of prototypes informs the next level of design, which, in turn, generates new prototypes, and the cycle continues. Beyer and Holzblatt (1998) suggest "A process is truly customer centered when customers can change designers' initial understanding of the work." Applying this approach avoids the often observed, "them that designed it should have to use it..."

Another important component of contextual research is thorough follow-up with consumers. Many companies shorthand this process by asking consumers to complete customer satisfaction surveys, but these surveys rarely allow for meaningful or open-ended feedback. Interactive follow-up may help manufacturers address small changes that could significantly improve product design.

A number of firms are recognizing the potential for smaller market segments and moving away from "one size fits all" mentality. The "limited customization" approach employed today is a step in that direction, and more applications are being introduced via web access. In this way, small batch production can be applied in efficient ways.

\section{THE BENEFITS OF INCLUDING THE USER}

Net benefits accrue to producing output that meets consumer expectations. As suggested, contextual research affords the needed information that shapes the prototypes, and eventually, the end products that fit the user's core needs. Kuniavsky (2003) offers five reasons for relying on a user-centered process.

1. Efficiency. Products that people actually want don't have to be remade. Products that are designed around the way people work don't need to be changed. When there's a model of how people use a product, there will be fewer disagreements, less ambiguity, less development delay, and you'll know just where to add functionality (and where not too)

2. Reputation. Users who have a positive user experience are more likely to keep using your product and to tell others to use your product. Products that match people's needs, desires, and abilities will create a level of satisfaction that goes beyond mere complacency and acquires an aura that extends beyond functionality. People associate themselves emotionally with the product, creating a bond that's much stronger than one that's merely based on rational functional trade-off.

3. Competitive Advantage. The more detailed the user model, the more easily it's possible to know which of their needs your product satisfies. This makes it possible to identify needs that are unfulfilled by the competition and drive innovation not based on technological capabilities (which may or may not have practical applications) but on real needs (which certainly do). Rather than reacting to user behavior, you can anticipate it and drive it.

4. Trust. When a product behaves according to people's expectations and abilities, they trust it more. Trustworthiness, in turn, leads to loyalty, satisfaction, and patience.

5. Profit. Ultimately, when a product costs less to make, costs less to maintain, attracts more customers, and provides better value to business partners (all things that are explicit goals of user experience research and design), it makes more money.

Some obvious benefits of including the user in the design process include improved communication, both inside and outside the firm; fewer customer complaints; higher perceived quality (with lower quality control costs); smoother scheduling in production due to reduced demand forecast errors; predictable development costs; more solid branding opportunities; improved responsiveness to market changes; and overall improvements in efficiency, which translates into greater control over all costs, affording pricing controls and/or improved profitability.

It may be a result of the on-going recession and a societal emphasis on environmentalism, or perhaps a deeper biological need unmet by today's virtual world, but consumers seem anxious to connect with their products in ways that result in longer-term ownership. Managing the process with this in mind is one way toward future success in product development. 


\section{AUTHOR INFORMATION}

George S. Lowry is Professor of Business at Randolph-Macon College in Ashland, Virginia where he has taught and served in a variety of administrative positions. George earned his $\mathrm{PhD}$ in Management from Virginia Commonwealth University and an M.S. in Business from Radford University. Prior to joining academia, he managed field and office operations for a commercial construction company. His research interests include applied finance, particularly regarding the European Union; pedagogical issues; and exploring dimensions of behavioral design. He has been active in his region's professional organizations, serving in leadership roles while encouraging faculty and students to become more professionally active.

Catherine Lowry Franssen is a National Science Foundation Teaching and Research Postdoctoral Fellow in Behavioral Neuroscience at Randolph-Macon College in Ashland, Virginia. Catherine earned her Ph.D. in Neurobiology from the University of Chicago and has worked as a Postdoctoral fellow at the University of California, Irvine and as Staff Neuroscientist at NeuroScience Associates based in Knoxville, TN. Catherine's research focuses on the neural underpinnings of seemingly innate or instinctual behaviors such as parenting, fear, and stress. In the classroom, at international conferences, and in local meetings, Catherine specializes in translating complex neurobiological concepts to daily life applications.

Jonathan E. Lowry, a Master of Design student at the University of Cincinnati focused on product design and development, design research, and design management will graduating in June 2011. In addition to graduate coursework, he has written for publications, delivered lectures, created and led in-class workshops, and helped establish curricula for emerging courses. Jonathan earned a BFA in Industrial Design in May 2008 from the Savannah College of Art and Design. His program offered significant coursework in product design, sustainability, and user centered design applying various research methods. Professionally, he has gained cross-disciplinary exposure at national academic and professional conferences.

\section{REFERENCES}

1. $\quad$ Ariely, Dan. (2010). The Upside of Irrationality. New York: Harper Collins.

2. Beyer, H. and Holzblatt, K. Contextual Design. San Francisco, CA: Morgan Kaufmann, 1998.

3. Brafman, Ori and Brafman, Rom. (2008). SWAY. New York: Crown Publishing Group.

4. Coppola, D.M., White, L.E., Fitzpatrick, D., \& Purves, D. (1998). "Unequal distribution of cardinal and oblique contours in ferret visual cortex". Proceedings of the National Academy of Sciences, 95, 2621-2623.

5. Crawford, Matthew B. (2009). Shop Class as Soulcraft. New York: Penguin Press.

6. $\quad$ Fink, L. Dee. (2003). Creating Significant Learning Experiences. New York: John Wiley \& Sons, Inc.

7. $\quad$ Gorman, Carma, ed. (2003). The Industrial Design Reader. New York: Allworth Press.

8. Holtzblatt, Karen; Wendell, Jessamyn Burns; and Wood, Shelley. (2005). Rapid Contextual Design: a How-To Guide to Key Techniques for User-Centered Design. San Francisco. Morgan Kaufmann Publishers.

9. Kelly, Tom. (2001). The Art of Innovation. New York: Doubleday.

10. Kelly, Tom. (2004). The Ten Faces of Innovation. New York: Doubleday.

11. Kuniavsky, Mike. (2003). Observing the User Experience: a Practitioner's Guide to User Research. San Francisco. Morgan Kaufmann Publishers.

12. Lambert, K.G. (2008). Lifting Depression: A Neuroscientist's Hands-On Approach to Activating Your Brain's Healing Power. Basic Books.

13. Lin, D.Y., Shea, S.D., Katz, L.C. (2006). Representation of natural stimuli in the rodent main olfactory bulb. Neuron, 50, 937-949

14. Lockley, S.W., Brainard, G.C., Czeisler, C.A. (2003). High sensitivity of the human circadian melatonin rhythm to resetting by short wavelength light. Journal of Clinical Endocrinology \& Metabolism, 88(9), $4502-4505$.

15. Louv, Richard. (2008). Last Child in the Woods: Saving our children from nature deficit disorder. New York: Algonquin Books.

16. Norman, Donald. (2002). The Design of Everyday Things. New York: Basic Books.

17. Norman, Donald. (2007). The Design of Future Things. New York: Basic Books. 
18. Norman, Donald. (2004). Emotional Design. New York: Basic Books.

19. Pirsig, Robert M. (2005). Zen and the Art of Motorcycle Maintenance. New York: Harper Perennial Modern Classics.

20. Sennett, Richard. (2009). The Craftsman. New Haven: Yale University Press.

21. Stumpf, Bill. (1998). The Ice Palace That Melted Away. New York: Random House.

22. Vgontzas, A., Bixler, E., Kales, A., (2000). Sleep, sleep disorders, and stress, in Fink, ed., Encyclopedia of Stress, San Diego: Academic Press, vol. 3, 449. 